\title{
Ciências Moleculares - um Curso de Excelência para a Formação de Cientistas
}

Fabio Armando Tal*

Coordenador do Curso de Ciências Moleculares

Instituto de Matemática e Estatística da Universidade de São Paulo

* Autor para correspondência: fabiotal@ime.usp.br

\section{RESUMO}

Neste relato, descrevemos uma experiência de graduação multidisciplinar, o Curso de Ciências Moleculares da USP, criado há 25 anos. São discutidos os princípios que nortearam a criação do projeto, como se deu sua implementação, as dificuldades próprias de um curso que relaciona diferentes campos do conhecimento e os resultados obtidos até o momento.

Palavras-chave: Multidisciplinaridade; Liberdade Curricular; Iniciação Científica.

\begin{abstract}
This report describes the experience of a multidisciplinary undergraduate course with 25 years of existence, the Molecular Sciences Program of USP. It discusses the initial goals of the project, its implementation, the specific difficulties faced in a program dealing with different areas and expertise, and the results obtained so far.
\end{abstract}

Keywords: Multidisciplinary, Curricular freedom, Undergraduate Scientific Research Projects.

\section{Introdução}

Há 25 anos, a Universidade de São Paulo percebia a necessidade de preparar alunos para interagir com diferentes áreas do conhecimento científico e atuar no espaço cada vez mais relevante da interface entre essas áreas. Se nos dias de hoje a ideia de "borrar fronteiras" é bastante difundida como algo natural e necessário para a produção científica, dados os avanços realizados por cientistas na interface de diversas áreas, no início da década de 1990 investir em um curso multidisciplinar de formação de pesquisadores era algo absolutamente fora do padrão.

Também pode ser considerada fora do padrão a profundidade com que a ideia foi levada a cabo frente às dificuldades iniciais. Afinal, como formar um jovem pesquisador capaz de transitar com eficiência entre várias áreas se os próprios docentes não tinham tal formação ou treino para isso, e se a estrutura de cursos da USP não permitia um acesso múltiplo a diferentes disciplinas que precisariam ser ministradas com níveis equivalentes de aprofundamento? Além disso, um curso com esse objetivo deveria, por princípio, permitir que o aluno ampliasse o máximo possível seu campo de atuação, o que exigiria garantir-lhe uma oferta constante de informações altamente atualizadas e liberdade inaudita para montar seu próprio percurso acadêmico.

\section{O Curso de Ciências Moleculares}

Após um longo processo de elaboração, a implementação do Curso de Ciências Moleculares (CGM) foi definida nos moldes de um curso experimental. A estrutura dele baseava-se então em três pilares, válidos até hoje:

1. Formação de base multidisciplinar - o curso conta com dois anos de ciclo básico, durante os quais se transmitem conhecimentos nas disciplinas de matemática, física, química, biologia e computação instrumental e não-instrumental. Todo o conteúdo ministrado nesse período inicial deve 
assegurar ao aluno uma base suficientemente ampla de conhecimentos para que ele possa estruturar suas escolhas subsequentes;

2. Liberdade de escolha do aluno no ciclo avançado - após os dois anos de ciclo básico, o aluno inicia um novo período de dois anos, que se volta ao desenvolvimento de sua autonomia acadêmica e direcionamento de interesses. Durante o ciclo avançado cada aluno desenvolve: a) um currículo individualizado; e b) um projeto de pesquisa pessoal. Sua grade curricular e projeto de iniciação científica são desenhados individualmente sob a supervisão de um professor orientador e acompanhados de perto pela direção do curso. Para produção da grade, o CCM rompe com os pré-requisitos formais e dá acesso, quando pertinente, a quase todas as disciplinas de graduação ou mesmo pós-graduação da universidade. Nesse estágio do processo, o curso deve fazer o máximo possível para promover o acesso do aluno aos meios para desenvolver seu projeto, inclusive estabelecer parcerias com professores de diferentes departamentos da universidade e até mesmo com pesquisadores e instituições externos, quando necessário e pertinente ao projeto do estudante. Além da quase total liberdade curricular e de orientadores, tal fase se caracteriza por também promover a internacionalização da graduação.

3. Busca por excelência - o CGM foi idealizado para possibilitar a formação e o aprimoramento de pesquisadores de qualidade mundial, aptos a interagir na fronteira de áreas. Com esse propósito, tanto a formação básica deve ser suficientemente abrangente para que os alunos possam se direcionar a diferentes campos quanto a formação avançada precisa ser verdadeiramente aprofundada para que os projetos desenvolvidos sejam significativos como a primeira experiência científica desses estudantes. Esses objetivos só podem ser alcançados se for constantemente exigido dos discentes um desempenho alto em todas as etapas, que justifique o grande investimento da universidade neles. Assim, a seleção ocorre por transferência interna e, ao mesmo tempo, garantem-se todas as vagas de origem. Caso algum aluno não consiga acompanhar o ritmo esperado ou mude de interesses, ele tem a opção de retornar à sua escolha de curso anterior.

A implementação de um curso tão singular foi muito controversa. Na época, realmente representou uma aposta inédita e corajosa da reitoria do Prof. Roberto Leal Lobo e Silva Filho, e foi o apoio contínuo das diversas pró-reitorias de graduação que permitiu ao CCM se desenvolver e estabilizar, deixando, com o tempo, de ser um curso experimental.

Uma proposta como a do CGM requer algumas condições específicas para acontecer, como interação entre diversos institutos de pesquisa da USP e o "empréstimo" de docentes que cooperem na formulação de cursos e componham a grade de aulas, além do citado apoio institucional. Como diferentes institutos têm diferentes concepções de ciência, para evitar que uma se sobreponha às outras o curso fica sediado diretamente na Pró-Reitoria de Graduação, mas conta com uma comissão diretora e uma comissão de graduação formada por representantes dos institutos de ciência natural básica.

\section{Os Alunos}

Um dos aspectos fundamentais do sucesso do curso está no perfil dos alunos selecionados. Em geral, são discentes com alto rendimento escolar e recém-matriculados na USP. Eles conhecem o GCM por meio de apresentações e palestras promovidas após o início do ano letivo, e, no caso de interesse, inscrevem-se para o processo seletivo. $\mathrm{O}$ aluno selecionado ingressa no curso no meio do semestre.

Dentre esses alunos, busca-se um determinado perfil: jovens muito interessados em ciência, que gostem de aprender e busquem desafios. Também se espera que eles tenham boa capacidade de trabalhar em equipe e de aprender uns com os outros, e que suportem um ritmo de ensino mais intenso que o esperado nos cursos tradicionais de graduação. Desde o início, parte-se do princípio de que todo o conteúdo do ensino médio já foi dominado pelos estudantes, e aqueles que eventualmente apresentarem alguma lacuna em 
sua formação anterior deverão compensá-la paralelamente, com a orientação dos professores. Por ser um curso altamente exigente, a seleção é bastante criteriosa e conta com etapas de prova escrita e dinâmicas de grupo, além de eventual análise de currículo escolar. A ideia durante o processo seletivo não é, de maneira alguma, compor um grupo de "gênios" de qualquer natureza, mas sim identificar aqueles alunos que verdadeiramente se interessem, tenham a base necessária e aspirem a seguir uma carreira de pesquisador. Mais do que estar disposto a estudar, espera-se que esse graduando tenha o desejo de ampliar sua visão e superar seus próprios limites acadêmicos, e que possa de fato dedicar-se a isso. A contrapartida encontra-se em uma formação de excelência, liberdade curricular e acompanhamento individualizado ainda durante a graduação, com alta probabilidade de concluir o curso já engajado em um projeto de continuação de pesquisa no Brasil ou no exterior.

Em função de sua natureza interdisciplinar, o CGM também pressupõe que o aluno tenha interesses abrangentes, bem como a capacidade de estabelecer relações complexas e criar pontes entre diferentes áreas. Com isso, busca-se o tempo todo, com a devida orientação docente, estimular soluções criativas para os problemas e atividades propostos, e desenvolver, nesse aluno, autonomia suficiente para, qualquer que seja a área de concentração escolhida, torná-lo capaz de integrar, ou mesmo abrir, novas frentes de pesquisa no futuro. A busca por esse perfil acaba favorecendo a formação de turmas em que o interesse pela ciência é comum e altamente valorizado, e em que os discentes encontram parceiros de diálogo e compartilhamento de interesses que em outros espaços são menos frequentes. Graduandos com aptidões diferentes também se auxiliam nas diversas disciplinas ao longo do curso, fortalecendo as relações e iniciando uma prática de colaboração científica com pessoas de outras áreas que muitos levam para sua carreira futura.

Em função de todas essas características, o curso se organiza de forma a poder flexibilizar seu conteúdo, mantendo uma base comum a todos e oferecendo mais - conteúdo ou aprofundamento - aos alunos que tenham essa demanda. A ideia é sempre ofertar recursos que permitam ao bom estudante continuar estimulado. Isso exige um acompanhamento próximo da turma por parte dos professores, e um olhar individualizado que permita ao professor, na medida do possível, reconhecer as demandas e limites de cada um. Encontrar esse equilíbrio é um dos desafios da prática educacional no CGM, que os anos de experiência vêm aprimorando.

Dentre os demais desafios enfrentados pelo CCM em suas práticas diárias, destacam-se ainda a necessidade de manter sua base curricular sempre atualizada e alinhada às mais recentes pesquisas em cada área, e a de aumentar a divulgação do curso para que mais alunos com perfil compatível possam participar dos processos seletivos. De forma geral, a direção e coordenação do CGM consideram que houve muitas melhorias aos longos dos anos, e o curso, já com uma tradição consolidada, torna-se a cada dia mais eficiente.

\section{Conquistas}

Passados 25 anos de sua criação, podemos hoje melhor avaliar os resultados do projeto concebido em 1990, e estes são marcantes. Cerca de 90\% dos egressos chegam a obter um título de mestre ou superior, e 75\% conseguem título equivalente a um doutorado. De todos os alunos formados pelo CCM até hoje, 60\% desenvolveram parte relevante de suas carreiras ou formação acadêmica fora do país, muitos se vinculando a instituições renomadas como Harvard, MIT, Oxford, Yale, entre outras. Entre os ex-alunos com dez anos de carreira, um em cada oito agora ajuda a USP como parte do seu corpo permanente de docentes e pesquisadores, e mais da metade é pesquisadora atuante em outras instituições de ensino superior ou institutos de pesquisa, tanto no Brasil quanto no exterior. Além dos resultados individuais, o curso também serviu pra validar algumas práticas e tendências educacionais que agora se difundem na universidade, como a diminuição dos pré-requisitos de disciplinas e a viabilidade de projetos interdisciplinares. 
Pessoalmente, pude acompanhar quase todo o histórico e desenvolvimento do CGM, primeiro como aluno da $5^{\mathrm{a}}$ turma, depois, já como docente ligado ao Instituto de Matemática e Estatística da USP, atuando como professor no ciclo básico e como orientador de projetos do ciclo avançado, e finalmente como coordenador atual do curso. É com grande prazer que, hoje, contribuo com esta alternativa fundamental de formação científica oferecida pela Universidade, retribuindo o investimento recebido quando aluno e a dedicação dos que me antecederam.

\section{Referências Bibliográficas}

NEWELL, William H. "Designing Interdisciplinary Courses". New Directions for Teaching and Learning, n. 58, (verão) 1994, pp. 35-51.

HALL, Pippa, and WEAVER, L. "Interdisciplinary Education and Teamwork: a Long and Winding Road". Medical Education, vol. 35, n. 9, 2001, pp. 867-875.

HEALEY, Mick \& JENKINS, A. Developing Undergraduate Research and Inquiry. York, UK: Higher Education Academy, jun. 2009. Disponível em $<$ https://www.heacademy.ac.uk/sites/default/files/developingundergraduate_final.pdf $>$. Acessado em 20 jun. 2016.

Publicado em 05/07/2016. 